\title{
ENGINE SYSTEM LOADS DEVELOPMENT FOR THE FASTRAC 60K FLIGHT ENGINE
}

\author{
Greg Frady* and Eric R. Christensen ${ }^{\dagger}$, Ph.D. \\ Sverdrup Technology MSFC Group \\ Huntsville, Alabama \\ Katherine Mims ${ }^{\ddagger}$, Don Harris ${ }^{\S}$, Russell Parks ${ }^{\mathbf{I}}$, Joseph Brunty", Ph.D. \\ NASA George C. Marshall Space Flight Center \\ Huntsville, Alabama
}

\begin{abstract}
$\underline{\text { Abstract }}$
Early implementation of structural dynamics finite element analyses for calculation of design loads is considered common design practice for high volume manufacturing industries such as automotive and aeronautical industries. However, with the rarity of rocket engine development programs starts, these tools are relatively new to the design of rocket engines. In the new Fastrac engine program, the focus has been to reduce the cost to weight ratio; current structural dynamics analysis practices were tailored in order to meet both production and structural design goals. Perturbation of rocket engine design parameters resulted in a number of Fastrac load cycles necessary to characterize the impact due to mass and stiffness changes. Evolution of loads and load extraction methodologies, parametric considerations and a discussion of load path sensitivities are discussed.
\end{abstract}

\subsection{Introduction}

The Fastrac engine is a 60,000 pound thrust liquid oxygen/kerosene (LOX/RP-1) engine being designed and developed at the NASA Marshall Spaceflight Center (MSFC). The Fastrac (Figure 1) is a singlestage, gas-generator cycle engine that utilizes one turbopump, a single-use combustion chamber and bell-shaped nozzle. The nozzle uses an ablative liner within a graphite composite overwrap. The first planned use of the Fastrac is in the X-34 vehicle.

The X-34 technology testbed demonstration vehicle (Figure 2) is a NASA program intended to demonstrate key technologies applicable to the Reusable Launch Vehicle (RLV) Program'. The objective of the X-34 is flight demonstration of key reusable launch vehicle operations and technologies directed at the RLV goal of low-cost space access. Key technologies include composite primary and secondary airframe structures, composite reusable propellant tanks, cryogenic insulation and propulsion system elements, advanced thermal protection systems and materials, low-cost avionics, integrated vehicle health monitoring systems, and flush air data systems. The X-34 vehicle will be a winged vehicle with a wing span of 27.7 feet and a length of 58.3 feet. In a typical X-34 flight, the testbed vehicle will be dropped from an L-1011 aircraft, the engine will start and accelerate the vehicle to Mach 8 . The vehicle will climb up to 250,000 feet, followed by a coast phase, re-entry and horizontal landing on a conventional runway.

This paper describes the work done at MSFC to simulate the structural dynamic response of the Fastrac engine system. The primary purpose of this analysis is to calculate the predicted dynamic loads on engine components and interfaces for use in component stress analysis and design. Engine components and interfaces include items such as ducts, brackets, gimbals, gimbal actuators, etc. The analysis utilizes a finite element model (FEM) of the engine system including all major components and vehicle interfaces. The engine is being tested in various configurations, all of which have been modeled by the Fastrac FEM. The configurations analyzed include the X-34 flight configuration, the Propulsion Test Article (PTA) ground test configurations, and the Horizontal Test Facility (HTF) ground test configurations. Each configuration may include several different sized nozzles and each has different support boundary conditions and

*Senior Engineer I, Engineering Directorate

${ }^{\dagger}$ Engineering Specialist, Associate Fellow AIAA

${ }^{\ddagger}$ Dynamics Engineer, Structural Dynamics/Loads Group ED21, AIAA Member

'Dynamics Engineer, Structural Dynamics/Loads Group ED2I

'Dynamics Test Engineer ED73

Dynamics Engineer, Structural Dynamics/Loads Group ED21

"Copyright $@ 2000$ by the American Institute of Aeronautics and Astronautics, Inc. All rights reserved." 
propellant feedline stiffness' which must be taken into account. The dynamic analysis has been done through a series of load cycles. The current load cycle is 9 . The results of load cycles 1-4 were described in an earlier work ${ }^{2}$. The following sections will describe the model and the input environments, emphasizing the changes made in load cycles 5-9. Selected results from load cycles 5-9 will then be discussed, concluding with the current status and future plans for this analysis.

\subsection{Finite Element (FE) System Model Construction}

The main components of the engine system FEM consist of the nozzle, the manifold assembly, the turbopump and gas generator, the ducts, the brackets, and the vehicle interfaces. The model was constructed using MSC/NASTRAN and MSC/PATRAN software and is pictured in Figure 3. The model was constructed using design drawings and electronic engine assembly geometry files for alignment and construction of duct and bracket models. During design iterations, new electronic files were provided along with the dimensional drawings for the use of incorporating design modifications into the model. Descriptions of each of the major engine component models created are given below.

\subsection{Chamber/Nozzle and Manifold Assembly}

The chamber/nozzle, shown in Figure 4, is composed of two main composite layers with several metallic inserts and over-bands. It is 74 inches long with a weight of approximately $528 \mathrm{lbs}$. The inner composite layer is composed of composite tape wrapped at an angle from the global longitudinal axis, and this layer is then overwrapped with a carbon epoxy tape that is wound in a helical pattern. For several reasons, which are explained in detail in Ref. 3 , the model of this structure for dynamic analysis required the use of composite plate elements rather than solid elements. To use these elements, the independent material properties of each layer of the composite lay-up had to be obtained for the element coordinate system. The properties required were the Young's modulus in the element axial direction, the Young's modulus in the circumferential direction, the shear modulus, and Poisson's ratio. Since the nozzle contour varies substantially along its length and since the tape was wound at two wrap angles, the material properties in the element coordinate system were different for each axial row of elements. Furthermore, the carbon epoxy overwrap was wound at a continually varying wind angle and therefore the overwrap material properties in the element coordinate system also vary with axial position. Substantial coordinate transformations were therefore required to obtain these properties from those obtained during material testing. This was accomplished by first using a FORTRAN program to read the wrap angle, wind angle, and cone angle for each axial row of elements, as calculated using a detailed spreadsheet incorporating the design geometry information. The derived transformations from the original tested properties were then used to calculate the plate element material properties. These properties were written to a material property card specifically for each element row and were then copied directly into the finite element data deck for modal analysis.

The nozzle model described above was modified when nozzle modal test data became available. This was done by adjusting the engineering constants such that calculated frequencies matched those measured from tests. The resulting scale factors varied from 0.65 for the tangential Young's modulus to 1.5 for the shear modulus. These scale factors were extrapolated for different nozzle ratios. For more details on the modal correlation of the nozzle, see Ref. 3 .

The manifold assembly is a very stiff, nearly rigid structure constructed of steel. This structure contains the main injector plate and the engine gimbal supports. It is modeled with QUAD4 and CTRIA3 plate elements.

\subsection{Turbopump and Gas Generator}

In the Load Cycle 1 model, the gas generator was modeled as an equivalent beam and the turbopump was modeled as a rigid mass. This rigid mass was connected to the turbopump brackets and the ducts via rigid link elements. A flexible beam or "stick" model for the turbopump was added in Ioad cycle 3 . A solid 3D model of the turbine housing was also created and used to calculate the housing modes and natural frequencies. The turbopump beam model cross-sectional properties were then modified to tune the bearn model with the first few modes and frequencies of the housing model. This tuned stick turbopump model has been used in load cycles 3-9.

\subsection{Ducts and Brackets}

The propellant ducts have circular cross-sections and were modeled using beam elements. For straight portions of the ducts CBEAM elements were used 
since these portions of the ducts behave according to simple beam theory. In the curved sections and the elbows, however, the CBEND element is used. In these portions of the pipe radial stress parallel to the radius of curvature will develop when the pipe bends and will cause the cross-section to deform into an oval shape which creates transverse stresses not present in a straight tube ${ }^{4}$. Therefore a $2 \mathrm{D}$ stress field is present within the pipe bend. This effect is included in the MSC/NASTRAN CBEND element.

The brackets which are used to attach components to the engine are modeled as elastic springs. The spring constants were determined by building a detailed 3D model of each bracket and calculating the displacements due to unit loads applied in the appropriate direction (see Figure 3).

\subsection{Vehicle Interfaces}

The interfaces between the engine system and the $\mathrm{X}$ 34 vehicle consist of the gimbal attachment, two gimbal actuators, and the feedline ducts. The actuators are attached to the engine using "belly bands" around the nozzle and are modeled as beams pinned at each end. At each of the interfaces the vehicle stiffness is modeled as a grounded elastic spring. The spring constants were calculated by the vehicle contractor and were determined from a finite element model with unit loads applied at the appropriate locations.

\subsection{Applied Loads and Environments}

There are six phases of engine operation that result in six sets of external forcing functions that were applied to the engine FE model as both static and dynamic loads. Since each phase of engine operation occurs at a different time, they are each considered as separate load conditions. These six phases are described in more detail below.

\subsection{Handling, Lifting, and Transportation Loads}

These are loads which result from handling, lifting, and transporting the Fastrac engine and are assumed to be $3 \mathrm{~g}$ in the $\mathrm{x}$ and $\mathrm{y}$ and $3.5 \mathrm{~g}$ in the $\mathrm{z}$ direction. These loads are applied as equivalent static loads.

\subsection{Separation Transient}

These are loads which result from the X-34 vehicle separating from the L1011 aircraft and occur prior to engine start. These loads are listed in Table 1 as load case 5.1 and are applied as equivalent static loads.

\subsection{Start and Shutdown}

These are the loads which result from the Fastrac engine startup and shutdown. A portion of this load results from quasi-static sources including the vehicle acceleration, static thrust, external aerodynamic load, and the engine gimbal acceleration. Another load resulting from the firing of the engine is the side load on the nozzle during thrust buildup and shutdown ${ }^{5-6}$. Engine startup/shutdown sideloads refer to the low frequency engine system response loads which occur within the first five seconds during the transient startup and within 2 seconds after shut-down. These are typically taken out through vehicle actuators and thrust structure and, because of their transient nature, are extremely unpredictable. The resultant shock response loads can occur at any angle on the interior nozzle wall with significant variability in frequency and amplitude. There are basically two major transient flow phenomena during start-up and shutdown which affect structural dynamic response of the engine system. The initial lateral sudden load on the nozzle occurs when the combustion process initiates. Then, as the core of the nozzle flow begins to exit the nozzle exit plane while the nozzle inner wall pressure equalizes with the outside pressure, the nozzle wall is affected by unsteady fluctuating pressures at the aft end of the nozzle ('tee pees'). Great efforts were expended in the past to analytically reduce the space shuttle main engine (SSME) sideloads; extensive testing was performed to statistically characterize scaling factors based on the $\mathrm{J}-2$ engine and derive forcing functions from time histories. In the end, it was determined that an initial conservative approach can be used which envelopes maximum expected sideloads. This conservative approach was selected for its timeliness to the Fastrac program.

For the Fastrac effort, the engine sideloads due to nozzle flow separation at start-up and again at shutdown were analyzed using simplifying assumptions based on results from previous engine programs such as the RS-27 and SSME. A maximum amplitude nozzle sideload was calculated for lateral application at the nozzle aft end and loads were calculated statically throughout the remainder of the engine interface. Based on past tests, a dynamic load factor of two was applied to the results, thus providing a conservative sideload. In addition, during initial ground testing it was discovered that some sideloads were present even during the steady-state operation. These steady-state side loads were much smaller than the startup sideloads and are due to the fact that the 
engine was operating at sea-level pressures during ground tests.

\subsection{Steady State Operation}

Two types of dynamic environments are induced by the operation of the engine itself. The first dynamic environment is due to the sinusoidal acceleration resulting from the rotation of the turbopump. The peak acceleration for the major frequency components of one, three, and six times pump synchronous operating speed were estimated and used in load cycles 1-3. As explained in Ref. 2, the magnitudes were decreased in load cycle 4 to the values given in Table 2 which have been used in all subsequent load cycles. These loads are applied at the turbopump $\mathrm{cg}$ with a $\pm 10 \%$ bandwidth about the excitation frequency.

The second dynamic environment resulting from the operation of the engine is the random acceleration due to sources in the turbopump, the gas generator, the combustion chamber, etc. The levels of random acceleration were determined using test data from the MA5 engine which is similar in design to the Fastrac. An initial random vibration spectrum was obtained by scaling and enveloping the peak responses obtained from the test data. The resulting environments are shown in Table 2.

In addition to the dynamic loads, during steady state operation there are also quasi-static applied loads due to vehicle acceleration (Table 1, load cases 6.1.1, 6.1 .2 , and 6.1.3), engine gimbal acceleration, and a $60,000 \mathrm{lb}$ static thrust load. The steady-state sideload described in section 3.4 was also applied to the system. This load was conservatively assumed to be the same magnitude as the startup/shutdown sideload.

\subsection{Re-Entry Loads}

These are quasi-static loads that result from the motion of the vehicle during re-entry. The loads are listed in Table 1 as load cases 7.1, 7.2, and 7.3.

\subsection{Landing Loads}

These are quasi-static loads which result during landing. The loads are listed in Table 1 as load cases 8.1 .

\subsection{Results}

A summary of the analysis results for load cycles 5-9 is given below. A description of the analysis methodology is given as well as changes made in the model and the applied loads and environments. This section will conclude by discussing several parametric analyses that were done using the system dynamic FEM in order to resolve some design issues.

\subsection{Engine Configurations}

As described earlier, there were several different engine configurations that were analyzed in support of both the flight configuration and ground test configuration.

The flight configuration consisted of the fastrac mounted on the X-34 vehicle with the $30: 1$ area ratio nozzle. The vehicle engine interfaces including the gimbal and actuator attachment point stiffness' were modeled as well as the vehicle propellant feedlines.

To date there have been two ground test configurations analyzed. The first was the Horizontal Test Facility (HTF) in which the engine was mounted horizontally on test stand B-1 at the NASA Stennis Space Center (SSC) (Figure 5). The HTF utilized the existing SSC propellant storage tanks and feedlines. The system model FEM boundary conditions were adjusted to match the HTF facility. The other ground test configuration was the Propulsion Test Article (PTA) (Figure 6). The PTA was designed to be a "flight-like" test setup in which the engine and propellant tanks are mounted in a truss structure called the "strongback". The strongback was mounted in the SSC B-2 test stand. Both the HTF and the PTA utilized a number of nozzles with different aspect ratios and materials.

Because of scheduling of other test articles at SSC, the Fastrac engine testing is being moved to a test facility at Santa Sousana, CA. Modeling of the configuration for this facility is still underway and no results are yet available.

\subsection{System Modal Test}

Two engine level modal surveys were performed for two different engine test configurations; the Fastrac engine mounted on the HTF and PTA test stands. The results from these tests are currently being incorporated into the global engine dynamic model with preliminary results indicating very good agreement between the model and measured test frequencies. 


\subsection{Quasi-static Analysis}

For each load cycle, the static response to a $1 \mathrm{~g}$ load was determined using MSC/NASTRAN Solution 101. Quasi-static load factors, including vehicle load factors (Table 1) and engine gimbal acceleration load factors were combined with other static loads like the thrust and side loads to determine the quasi-static loads acting on the engine components for all the quasi-static load cases.

\subsection{Dynamic Analysis}

As described in Ref. 2, the response to the sinusoidal environment is determined using the system FEM with an enforced acceleration at the turbopump $\mathrm{cg}$. For load cycles 5-9, a modal damping value of $3 \%$ was used. The MSC/NASTRAN modal frequency response solution (SOL 111) was used to calculate the dynamic loads on the component.

The methods used to calculate the response to the random vibration environment are described in more detail in Ref. 2. For the first few load cycles the system FEM was used with enforced accelerations applied via the NASTRAN large mass method at the turbopump, manifold, and gas generator. As explained in Ref. 2, this method led to unreasonably high loads due to pseudo-static response ${ }^{7}$ resulting from relative motion of the supports. A modified random response analysis approach based on component level analysis was then adopted. For certain components which could be approximated as having a "base drive" type of input, Miles' equation ${ }^{8}$ was used to calculate the random response. For other components such as the gas generator, turbopump, support brackets, etc., a quasi-static approach would be used. This quasi-static approach would consist of applying the composite random grms load as a static applied acceleration to each component individually in order to determine the support and interface loads and reactions. The large mass method was used for analyzing the feedline ducts which were long, unsupported structures.

\subsection{Parametric Analysis}

As with any developmental program, design parametrics are critical in achieving the design needed to meet the mission goals. As the engine design matured, there remained numerous negative stress margins of safety. Some of these negative margins were due primarily to dynamic loads. In order to determine the effect of various design configurations on the dynamic loads, the Fastrac engine dynamic model was utilized for a number of parametric analyses. In particular, three parametric studies have proved to be very useful during the development of this engine. The first study was an analysis of the duct sensitivities and the second involved changing properties of the composite nozzle during the engine burn. The third analysis involved the HTF feedline ducts.

Since the design of the Fastrac engine is integral (i.e., the turbopump is directly connected to the composite nozzle), the load paths are sensitive to small changes throughout the engine system. The top of the turbopump is attached to the main injector just above the main injector/nozzle interface. The lower turbopump attachment is at the belly band of the composite nozzle. A number of ducts run from the turbopump to the main injector carrying LOX and RP. Due to the LOX and RP lines and the stiffness of the turbopump attachments, the ducts have some load carrying capabilities. The dynamic system model was used to perform a parametric analysis to determine how to reduce the loads in the turbopump RP discharge duct that leads into the main injector (Figure 7). Two design conditions were compared in this analysis. In one design, a bracket was added to the RP discharge duct between the RP Adapter Block and Main Injector. This bracket, designated the "splitter bracket", was simulated in the system FEM by linear springs elements in the $x, y$, and $z$ directions. The second design had no bracket and the duct was left unsupported at that point. The results of the analysis indicated that with the splitter bracket, the dynamic loads decreased enough to eliminate a total of four negative margins in the RP Discharge Duct and RP Injector Ducts. Because of these results, the splitter bracket design was used in the Fastrac.

Another parametric analysis was used to determined the effects the nozzle had on the system dynamics during the engine burn. The nozzle used for this engine is a two-layer composite nozzle. The bond between the two composite layers has proven to be temperature sensitive, causing the modal characteristics of the nozzle to change by over $40 \%$ while the engine is burning. These changes in the modal characteristics cause a number of shifts in both the static and dynamic loads during the ascent into orbit. To perform the parametric analysis, a number of nozzle models that had been correlated with modal test data were inserted into the system model. These nozzle models were correlated using test data from actual nozzle firing tests that measured data at 0,25 , 50,100 , and 150 second burn times. ${ }^{9}$ The nozzle 
stiffness not only affected the dynamic loads, it also affected the internal load paths of the engine itself, increasing or decreasing loads in the ducts and adjacent hardware components. The goals of the parametric analysis was to run loads for the sinusoidal and selected static load cases in order to identify how many nozzle burn time cases would be needed to envelope all the dynamic loads for all load cases and all load interfaces throughout the engine.

The static load cases examined were the lgx, lgy, 1gz, side load, and axial thrust load cases. Utilizing plots of the load interfaces with respect to each load component, The static analyses were used to determine the peak static loads during the run for each burn time nozzle model (An example is shown in Figure 8). It was determined that the static load cases could envelop all peak loads by analyzing the system with only the 0 and 150 second nozzles.

A certain amount of engineering judgment was required to assess the number of nozzle burn times needed to envelop the majority of the peak loads due to the sinusoidal excitation. The choice centered around two issues. The first issue was whether the sinusoidal component of the loads was a main driver to the overall magnitude of the loads for the individual components. The second issue was whether the interface was considered a sensitive loads area due to having a low or negative stress margin of safety. This parametric analysis proved extremely important to the structural design of the engine components. As indicated in Figure 9, the results indicated that only three nozzle burn times were needed to envelop the peak load cases for all engine load interfaces throughout the engine. The 0,40 , and 150 second nozzle burn times were chosen with confidence that the peak loads would be enveloped in the engine stress analyses. All load cycles from load cycle 7 on included these nozzle burn cases.

The third parametric analysis was performed on the HTF facility feedline ducts. The initial design called for a support approximately 10 inches from the engine interface on the LOX feedline duct. A dynamic analysis determined that the constraint was too close to the engine interface causing excessively high loading on the engine. A redesign was requested and the support was removed.

\subsection{Conclusions}

Dynamic loads on the Fastrac engine have been generated for a total of 9 load cycles which have incorporated design changes, changes in environments, and changes in analysis methodology. Comparisons of loads cycles have been made. Because of various design configuration differences (including ground test hardware), engine design changes and occasional environments change, there is no single configuration or operating condition which yields worst case loads for all engine interfaces. The engine system FEM has proven to be a useful tool in analyzing changes in dynamic loads resulting from the evolving engine system design. As ground testing begins, hot fire data will become important as a critical tool to validate engine design loads. A successful full duration testing (approximately 160 seconds) of the HTF short nozzle engine configuration has been completed, and is the first of a number of ground tests to be conducted in which dynamic loads and environments will be measured. These test results will be used to verify and update the engine system model.

\subsection{References}

1. D. C. Freeman, T. A. Talay and R. E. Austin, "The NASA Reusable Launch Vehicle Technology Program", Presented at the Space '96 Conference: 5th International Conference and Exposition on Engineering, Construction, and Operations in Space, Albuquerque, New Mexico, June 5, 1996.

2. Christensen, E., Frady, G., Mims, K., Brown, A., "Structural Dynamic Analysis of the X-34 Rocket Engine", paper no. 98-2012 presented at the $39^{\text {in }}$ AIAA Structures, Structural Dynamics, and Materials Conference, April 20-23, 1998, Long Beach, CA.

3. Brown, A.M, and Sullivan, R.M, "Dynamic Modeling and Correlation of the X-34 Composite Rocket Nozzle", 1998 JANNAF Rocket Nozzle Technology Meeting, Salt Lake City, Utah, March 16-20, 1998.

4. R. Frick, "Determining Tube Stress From CBEND Element Forces and Moments", Presented at the MSC 1993 World User's Conference, Paper No. 64, Amy, 1993.

5. P.N. Fuller, "J-2S Nozzle Side-Load Study", Rocketdyne Engineering Final Report Contract NAS8-25156, August, 1972. 
6. W. Holland, "SSME/Side Loads Analysis for Flight Configuration", NASA TM X-64841, September, 1974.

7. P. Leger, I.M. Ide, and P. Paultre, "MultipleSupport Seismic Analysis of Large Structures", Computers and Structures, Vol. 36, No. 6, pp. 1153-1158, 1990.

8. J. Miles, "On Structural Fatigue Under Random Loading", Journal of Aeronautical Sciences, Vol. 21, No. 11, Nov. 1954, pp. 753-762.
9. Brown, A.M., "Temperature-Dependent Modal Test/Analysis Correlation of X-34 FASTRAC Composite Rocket Nozzle," submitted for the 2000 AIAA Structures, Structural Dynamics, and Materials Conference, April 3-6, 2000, Atlanta, GA.

Table 1. X-34 Vehicle Quasi-Static Load Factors

\begin{tabular}{|l|l|c|c|c|c|c|c|}
\hline & \multicolumn{1}{|c|}{ Event } & \multicolumn{2}{|c|}{ Load Factors } \\
\hline $\begin{array}{c}\text { Load } \\
\text { Case }\end{array}$ & \multicolumn{1}{|c|}{$\begin{array}{c}\mathbf{N x} \\
(\mathbf{g})\end{array}$} & $\begin{array}{c}\mathbf{N y} \\
(\mathrm{g})\end{array}$ & $\begin{array}{c}\mathbf{N z} \\
(\mathbf{g})\end{array}$ & $\begin{array}{c}\mathbf{R x} \\
\left(\mathbf{r a d} / \mathbf{s e c}^{2}\right)\end{array}$ & $\begin{array}{c}\mathbf{R y} \\
\left(\mathbf{r a d} / \mathbf{s e c}^{2}\right)\end{array}$ & $\begin{array}{c}\mathbf{R z} \\
\left(\mathbf{r a d} / \mathbf{s e c}^{2}\right)\end{array}$ \\
\hline 5.1 & Separation Transient & -0.20 & \pm 0.50 & 0.50 & 0.00 & \pm 4.35 & 0.00 \\
\hline 6.1 .1 & Pull-up Maneuver Random X & 2.50 & 0.00 & -2.64 & 0.00 & 0.00 & 0.00 \\
\hline 6.1 .2 & Pull-up Maneuver Random Y & 1.50 & \pm 1.00 & -2.64 & 0.00 & 0.00 & 0.00 \\
\hline 6.1 .3 & Pull-up Maneuver Random Z & 1.50 & 0.00 & -3.64 & 0.00 & 0.00 & 0.00 \\
\hline 7.1 & Re-entry Max Nz Random X & -1.50 & 0.00 & -5.00 & 0.00 & 0.00 & 0.00 \\
\hline 7.2 & Re-entry Max Nz Random Y & -0.50 & \pm 1.00 & -5.00 & 0.00 & 0.00 & 0.00 \\
\hline 7.3 & Re-entry Max Nz Random Z & -0.50 & 0.00 & -6.00 & 0.00 & 0.00 & 0.00 \\
\hline 8.1 & Landing (Enveloped) & -0.62 & \pm 0.93 & -3.15 & \pm 2.12 & 0.89 & \pm 0.38 \\
\hline
\end{tabular}

Table 2. Fastrac 60K Engine Self-Induced Random Vibration Environment

\begin{tabular}{|c|c|c|c|}
\hline $\begin{array}{c}\text { Turbopump and Exhaust } \\
\text { Duct }\end{array}$ & $\begin{array}{c}\text { Gimbal Block and Manifold } \\
\text { Assembly }\end{array}$ & $\begin{array}{c}\text { Valves, Sensors, Actuators, } \\
\text { etc. }\end{array}$ & Gas Generator \\
\hline $10 \mathrm{~Hz} @ 0.003 \mathrm{~g}^{2} / \mathrm{Hz}$ & $10-600 \mathrm{~Hz} @ 0.01 \mathrm{~g}^{2} / \mathrm{Hz}$ & $10-100 \mathrm{~Hz} @ 0.01 \mathrm{~g}^{2} / \mathrm{Hz}$ & $10 \mathrm{~Hz} @ 0.001 \mathrm{~g}^{2} / \mathrm{Hz}$ \\
\hline $10-600 \mathrm{~Hz} @ 1.7 \mathrm{~dB} / \mathrm{Oct}$ & $600-800 \mathrm{~Hz} @ 11.4 \mathrm{~dB} / \mathrm{Oct}$ & $100-300 \mathrm{~Hz} @ 2.9 \mathrm{~dB} / \mathrm{Oct}$ & $10-200 \mathrm{~Hz} @ 3 \mathrm{~dB} / \mathrm{Oct}$ \\
\hline $600-1300 \mathrm{~Hz} @ 0.03 \mathrm{~g}^{2} / \mathrm{Hz}$ & $800-2000 @ 0.03 \mathrm{~g}^{2} / \mathrm{Hz}$ & $300-700 \mathrm{~Hz} @ 0.03 \mathrm{~g}^{2} / \mathrm{Hz}$ & $200-800 \mathrm{~Hz} @ 0.02 \mathrm{~g}^{2} / \mathrm{Hz}$ \\
\hline $1300-2000 \mathrm{~Hz} @-2.9 \mathrm{~dB} / \mathrm{Oct}$ & & $700-1250 \mathrm{~Hz} @ 15.8 \mathrm{~dB} / \mathrm{Oct}$ & $800-1250 \mathrm{~Hz} @ 23.2 \mathrm{~dB} / \mathrm{Oct}$ \\
\hline $2000 \mathrm{~Hz} @ 0.02 \mathrm{~g}^{2} / \mathrm{Hz}$ & & $1250-600 \mathrm{~Hz} @ 0.6 \mathrm{~g}^{2} / \mathrm{Hz}$ & $1250-1600 \mathrm{~Hz} @ 0.6 \mathrm{~g}^{2} / \mathrm{Hz}$ \\
\hline & & $\begin{array}{c}1600-2000 \mathrm{~Hz} @-41.2 \\
\mathrm{~dB} / \mathrm{Oct}\end{array}$ & $\begin{array}{c}1600-2000 @-41.2 \mathrm{~dB} / \mathrm{Oct} \\
\end{array}$ \\
& & $2000 \mathrm{~Hz} @ 0.03 \mathrm{~g}^{2} / \mathrm{Hz}$ & $2000 \mathrm{~Hz} @ 0.03 \mathrm{~g}^{2} / \mathrm{Hz}$ \\
\hline Random Composite $=7.2 \mathrm{~g} \mathrm{rms}$ & Random Composite $=6.8 \mathrm{~g} \mathrm{rms}$ & $\begin{array}{c}\text { Random Composite }=21.0 \mathrm{~g} \\
\mathrm{rms}\end{array}$ & $\begin{array}{c}\text { Random Composite }=20.1 \mathrm{~g} \\
\mathrm{rms}\end{array}$ \\
\hline & & & \\
\hline Superimposed Sinusoids: & Superimposed Sinusoids: & Superimposed Sinusoids: & Superimposed Sinusoids: \\
\hline $2.0 \mathrm{Gpk} @ 335 \mathrm{~Hz}$ & $2.0 \mathrm{Gpk} @ 335 \mathrm{~Hz}$ & $2.0 \mathrm{Gpk} @ 335 \mathrm{~Hz}$ & $2.0 \mathrm{Gpk} @ 335 \mathrm{~Hz}$ \\
\hline $7.0 \mathrm{Gpk} @ 1000 \mathrm{~Hz}$ & $7.0 \mathrm{Gpk} @ 1000 \mathrm{~Hz}$ & $7.0 \mathrm{Gpk} @ 1000 \mathrm{~Hz}$ & $7.0 \mathrm{Gpk} @ 1000 \mathrm{~Hz}$ \\
\hline $7.0 \mathrm{Gpk} @ 2000 \mathrm{~Hz}$ & $7.0 \mathrm{Gpk} @ 2000 \mathrm{~Hz}$ & $7.0 \mathrm{Gpk} @ 2000 \mathrm{~Hz}$ & $7.0 \mathrm{Gpk} @ 2000 \mathrm{~Hz}$ \\
\hline
\end{tabular}



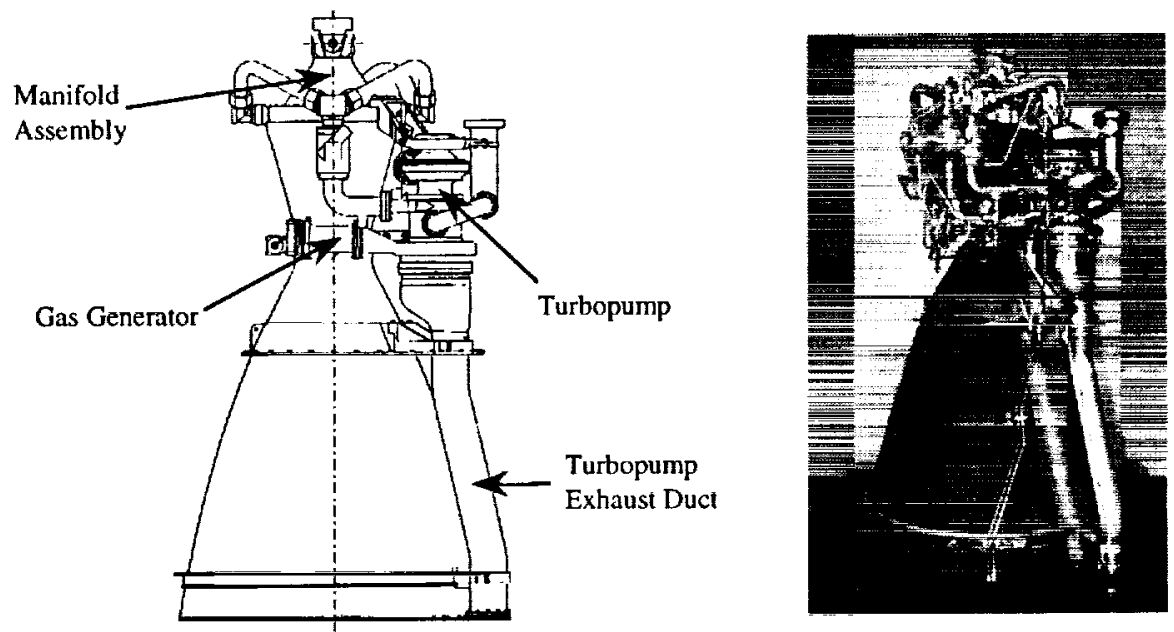

Figure 1. Fastrac 60K Engine

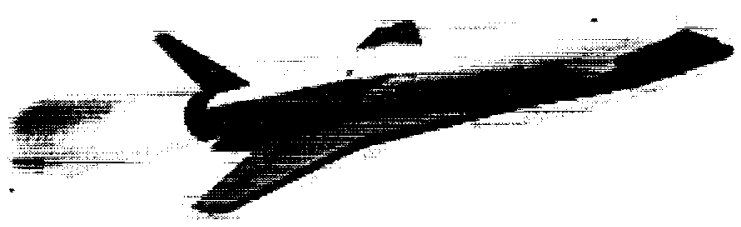

Figure 2. X-34 Vehicle

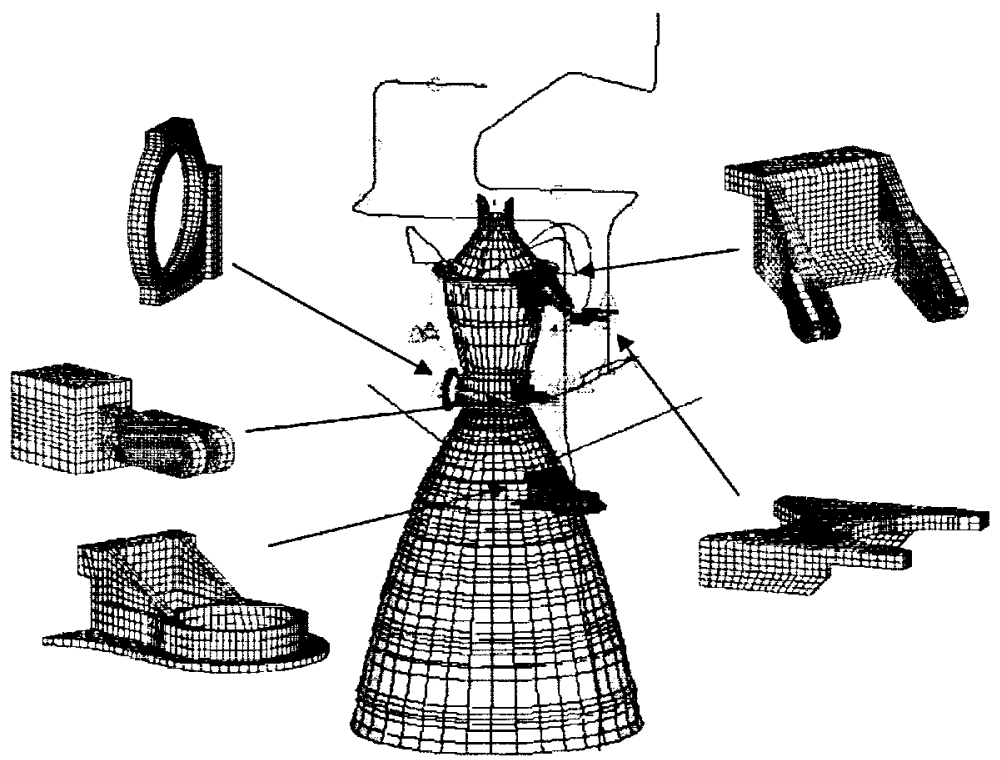

Figure 3. Engine System Dynamic FE Model 


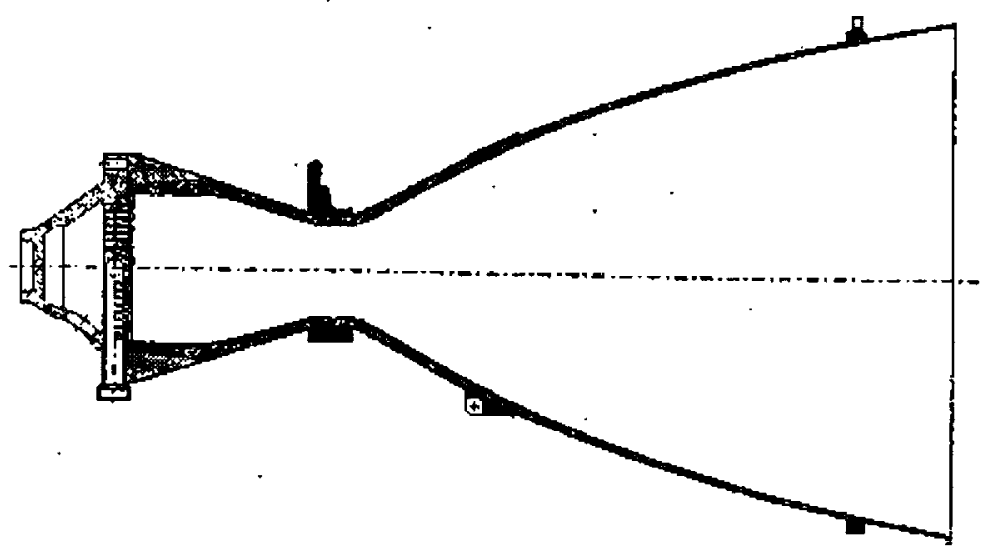

Figure 4. Composite Chamber/Nozzle

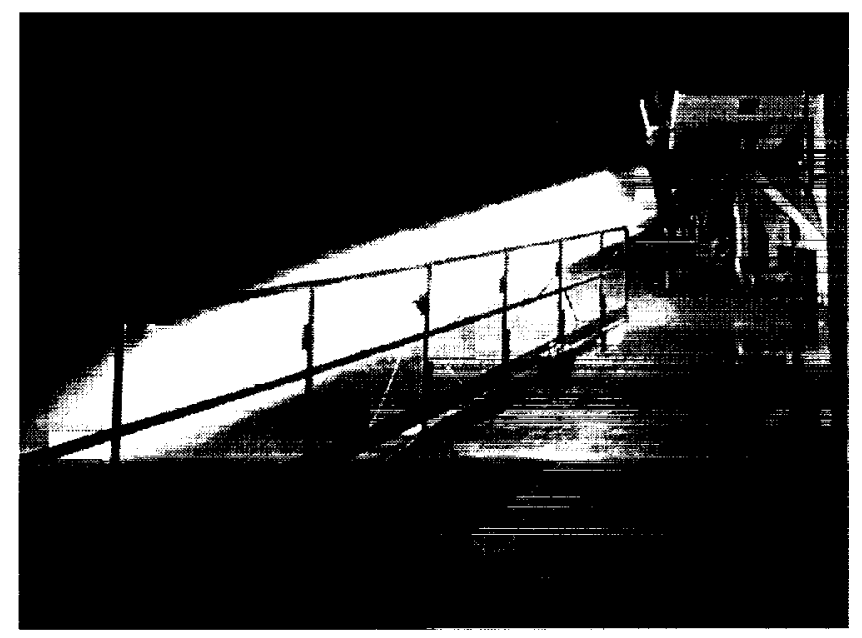

Figure 5. Horizontal Test Facility

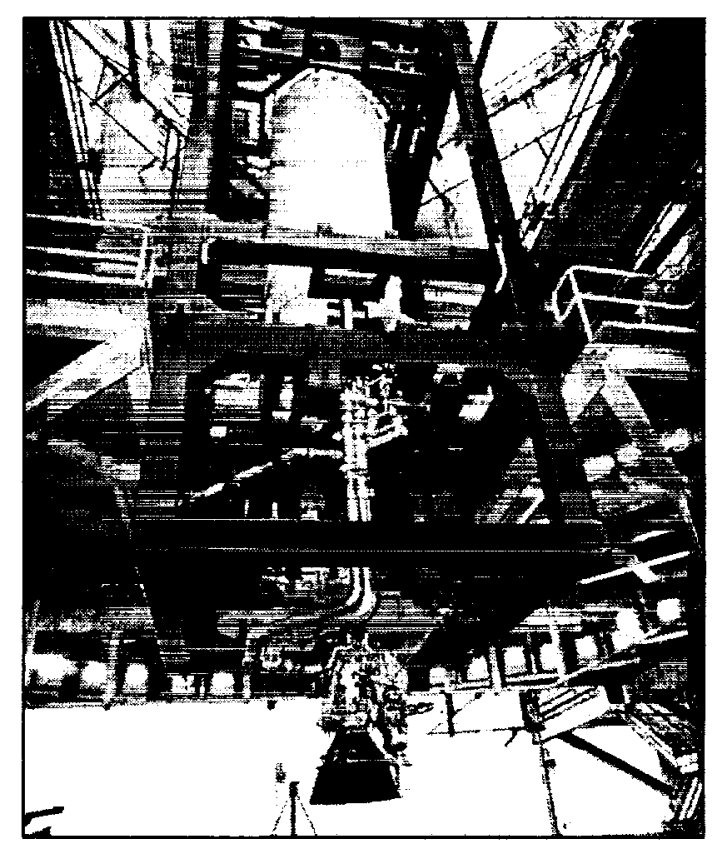

Figure 6. Propulsion Test Article (PTA) 


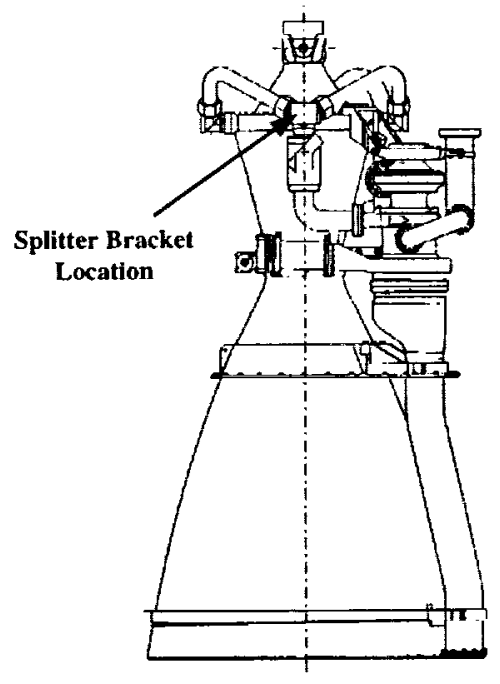

Figure 7. Splitter Bracket Location

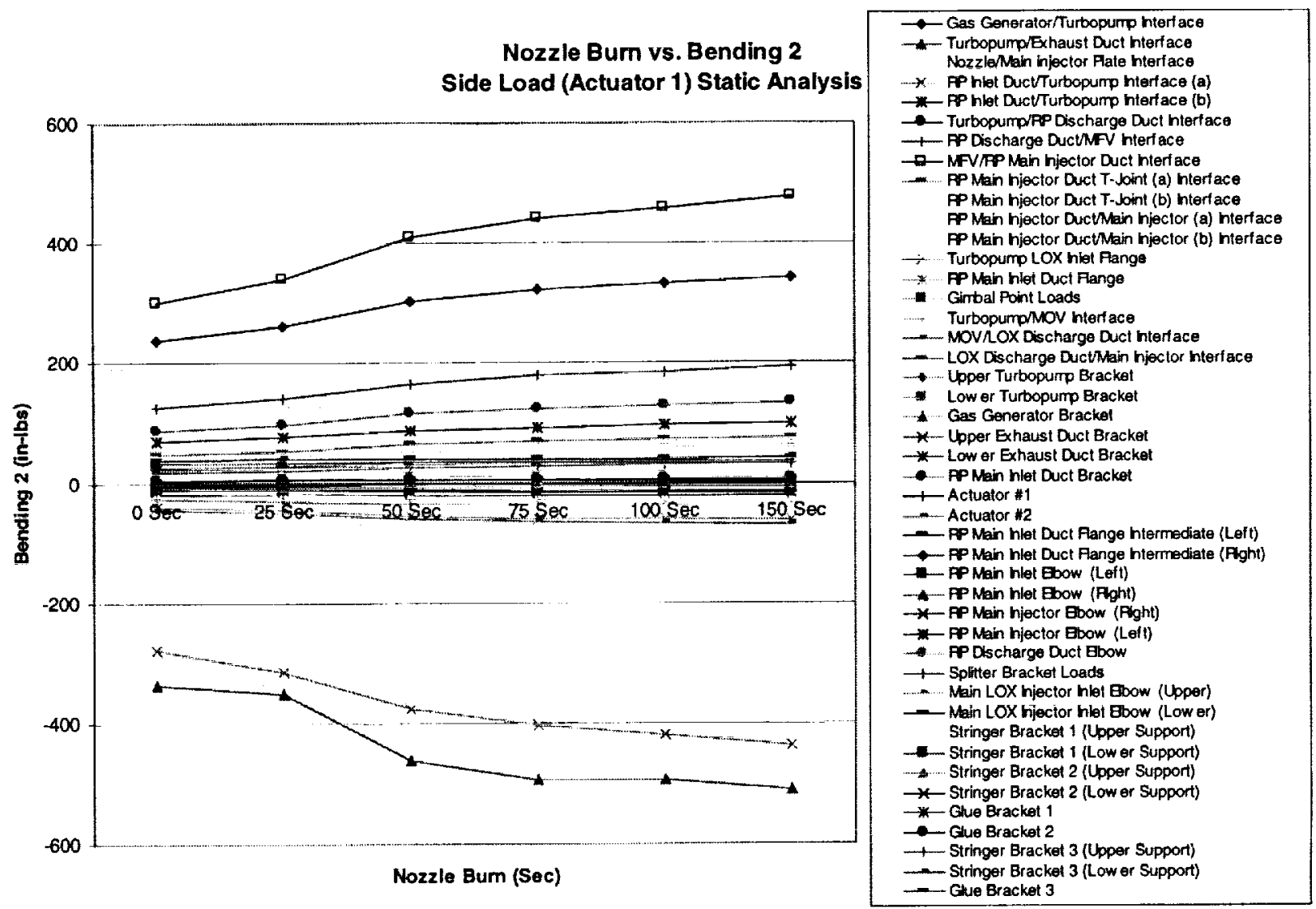

Figure 8. Static Load vs. Nozzle Burn Time

American Institute of Aeronautics and Astronautics 


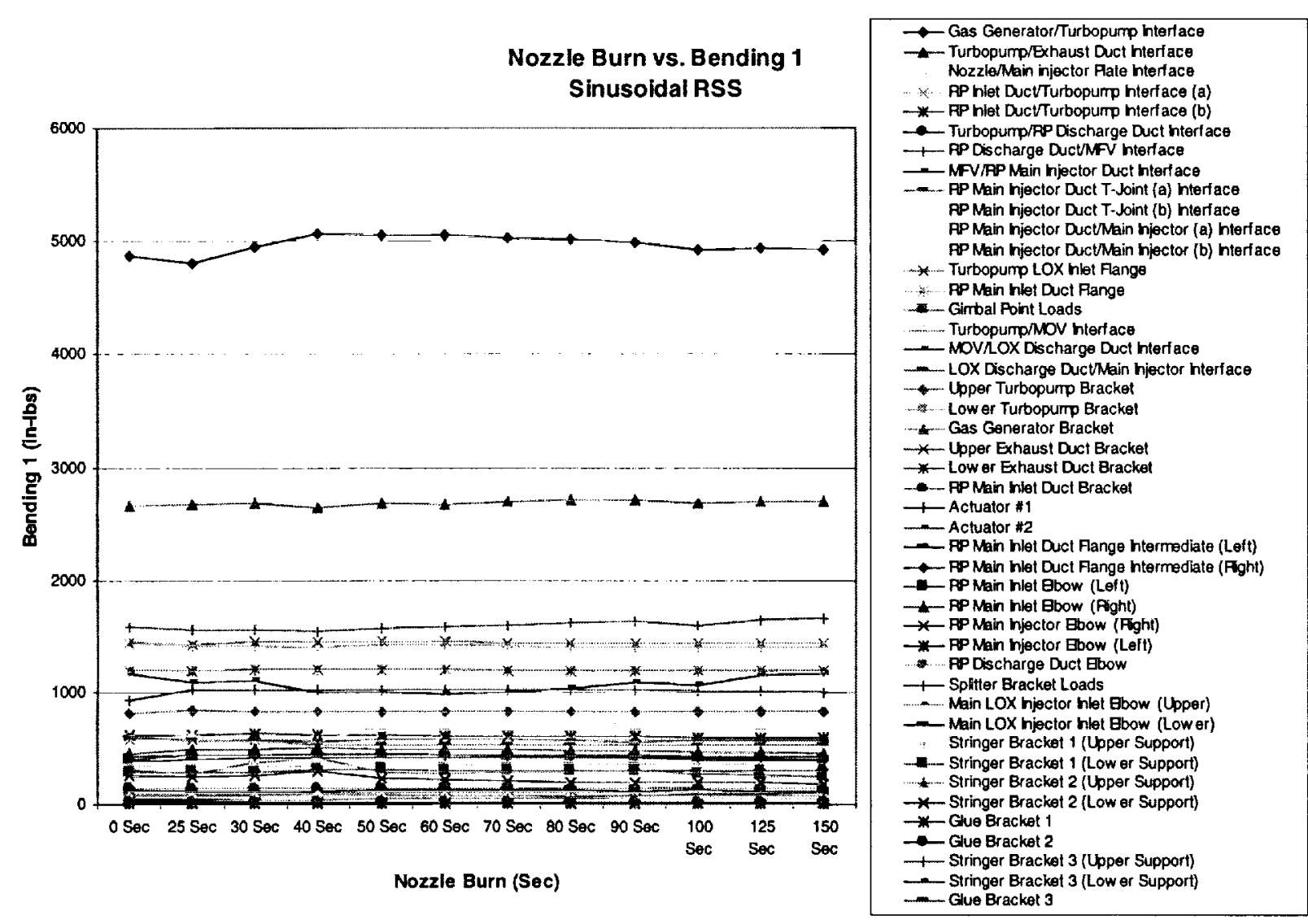

Figure 9. Peak Dynamic Loads vs. Nozzle Burn Tïme

II

American Institute of Aeronautics and Astronautics 
